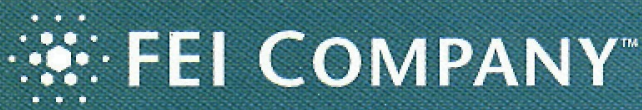

Those who succeed are always in control. They know what they want to do and how to do it best. In your fast paced, technologically challenging and demanding world, you make the crucial decisions. Having the right tools and support can be the difference between success and failure.

\section{IN CONTROL}

FEI Company puts you in contral, with the strength and experience to help you push your limits and performance. We support the world's leading manufacturers and researchers as they meet new challenges with our advanced TEM, ESEMMM, FIB and DualBeamin solutions. I's time to make your next move. Take control.

TAKE CONTROL WITH FEI

FEI Company

Tel: (503) 6407500 , Fax: (503) 8442615 hitp://wwwifeic.com/control 


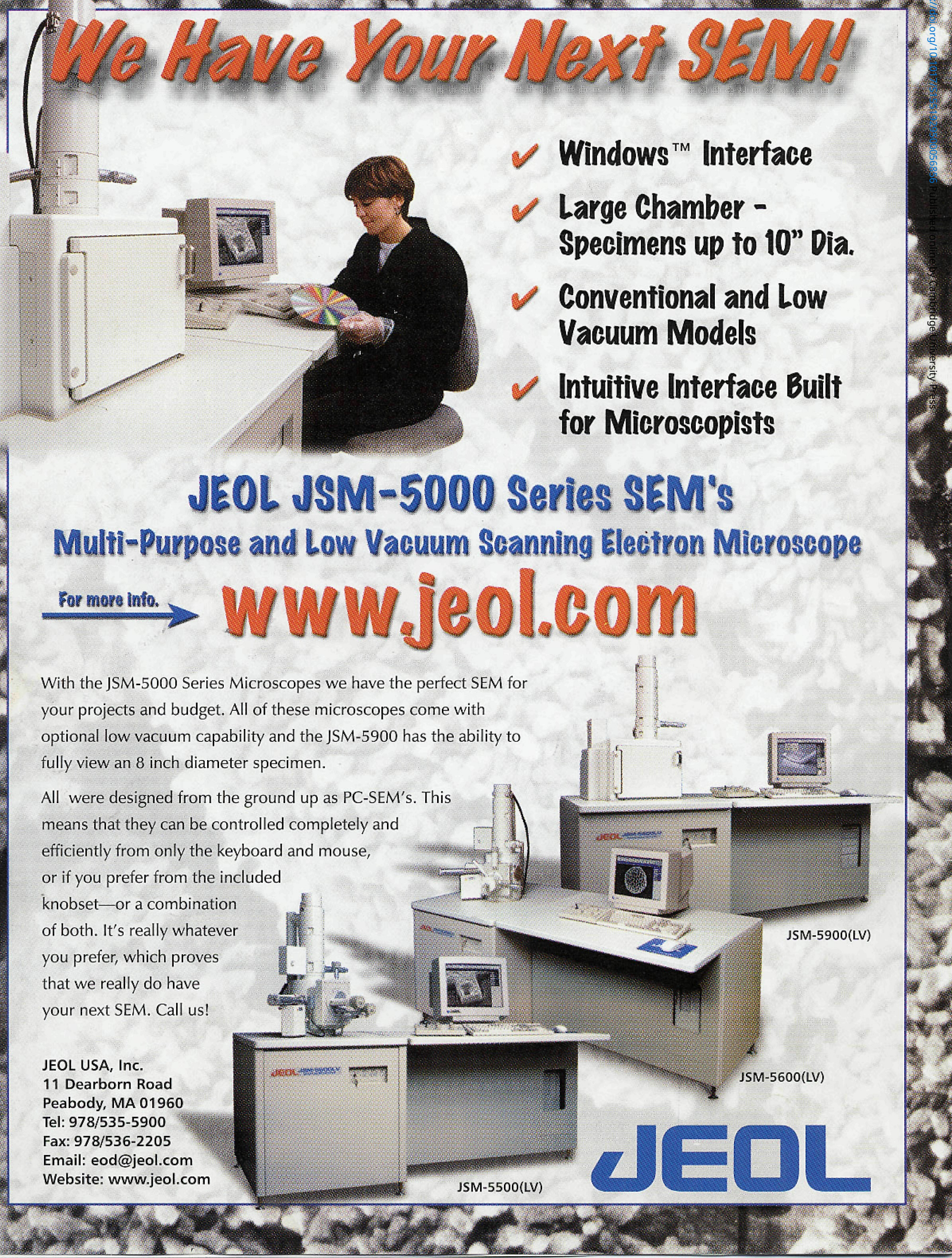

